\title{
Surface Characterization of DD6 Single Crystal Superalloy during Acid Etching at Different Temperatures
}

\author{
Lijie $\mathrm{Hu}^{1, \mathrm{a}}$, Jiarong $\mathrm{Li}^{1, \mathrm{~b}}$, Mei Han ${ }^{1, \mathrm{c}}$, and Shizhong Liu ${ }^{1, \mathrm{~d}}$ \\ ${ }^{1}$ Science and Technology on Advanced High Temperature Structural Materials Laboratory, \\ Beijing Institute of Aeronautical Materials, Beijing 100095, China \\ ahulijie20031@163.com, bjirong.li@biam.ac.cn \\ cmei.han@biam.ac.cn, ${ }^{\mathrm{d}}$ shizhong.liu@biam.ac.cn
}

\begin{abstract}
An experimental study was carried out to investigate the effect of acid etching on surface integrity of a single crystal nickelbased superalloy. The corrosion tests were conducted in solution of hydrochloric acid and hydrogen peroxide at different reaction temperatures. The corroded specimens were characterized by scanning electron microscopy, weight loss measurements and surface roughness measuring instrument. The results indicate that DD6 suffers serious selective corrosion at cold bath temperature due to unduly slow etching when immersed for the maximum time. It is found that preferential dissolution of $\gamma^{\prime}$ phase occurred, leading to the increase of surface roughness.
\end{abstract}

\section{Introduction}

Nowdays single crystal nickel-base superalloy are extensively used for aeroengine system because of their excellent mechanical properties and high corrosion resistance, the technological developments of single crystal superalloys have significantly raised the operating temperatures and efficiencies of gas turbines $[1,2]$. Most superalloys form a tenacious oxide coating because of their high content of oxide-forming metals, such as nickel, cobalt, aluminum and chromium [3]. All surface contaminants should be removed from superalloys before they are heat treated or subjected to service at elevated temperatures, meanwhile tarnish generally should be removed from components for improved finishing-joining operations. Meanwhile nickel-base alloys should be acid etched to prepare for subsequent nondestructive inspection. Acid etching is the most widely used methods for removing oxides or scale from heat-resistant alloys, in order of preference based on economic considerations [4].

Hydrochloric acid is usually used in acid etching solution, in order to remove surface contaminants, nitric acid, ferric chloride or hydrogen peroxide is frequently added in the etching solutions. However, because the acid solution attacks the base metal, this type of

* Corresponding author:hulijie20031@163.com 
attack creates not only an undesirable surface appearance but also creates pits that will serve to dramatically lower fatigue and/or creep-rupture properties of affected superalloys $[5,6]$, it is necessary to limit the etching parameters to prevent excessive metal loss or metal surface roughening.

Based on our knowledge, the corrosion behavior of the DD6 superalloy in the hydrochloric acid and hydrogen peroxide has not been dealt with in depth. In this study, the effect of bath temperature of acid etching was investigated, and dissolution behavior of DD6 single crystal alloy during acid etching was characterized.

\section{Experimental Procedures}

The second generation single crystal superalloy DD6 was used as experimental materials. The chemical composition of DD6 alloy was shown in the article [7]. DD6 single crystal superalloy plates, $130 \mathrm{~mm}$ in length, $25 \mathrm{~mm}$ in width, and $2.5 \mathrm{~mm}$ in thickness were directionally solidified using helical selecting method in a vacuum induction single crystal furnace with high temperature gradient, the crystal orientations of the specimens were determined by the X-ray diffraction method, and the deviation degree between principal stress axis and the [001] orientation was less than $15^{\circ}$. DD6 sheets in the as-cast condition were then cut to testing samples with size of $25 \mathrm{~mm} \times 10 \mathrm{~mm}$.

Analytical grade hydrogen peroxide and hydrochloric acid were used to prepare acid etching solution, the volume ratio of above mentioned chemical reagent was 1:10. The temperature was varied from $15{ }^{\circ} \mathrm{C}$ to $35^{\circ} \mathrm{C}$ adjusted by water bath heating. The testing specimen immersed in acid solution for the maximum time for twice, the operation completed when the bubbles disappeared. The reaction time depends upon bath temperature, it takes about 20 minutes for corrosion at $15{ }^{\circ} \mathrm{C}, 12$ and 8 minutes for $25{ }^{\circ} \mathrm{C}$ and $35{ }^{\circ} \mathrm{C}$ respectively.

Samples were first rinsed in tap water after etching. Samples used for weight loss measurement were slightly brushed to remove reaction products. Then the samples were dried and weighed. In order to characterize the cross section morphology, the samples obtained after acid pickling were rinsed in water, dried, mounted and polished. The surface and cross sectional morphology was characterized with scanning electron microscopy (SEM), the surface roughness, Ra was measured using a surface roughness tester.

\section{Results and Discussion}

Fig. 1 shows the surface roughness percentage $\Delta R_{a}$ obtained under different etching temperature.

$\Delta R_{a}$ is calculated in term of increasing percentages of the arithmetic mean roughness $R_{a}(\mathrm{Eq}$. 1) [8],

where $R_{a}^{0}$ is the initial workpiece value, and $R_{a}^{f}$ is the final value after etching.

$$
\Delta R_{a}=\left(R_{a}^{f}-R_{a}^{0}\right) / R_{a}^{0}
$$

Likewise, bath temperature significantly influence surface roughness performance of corroded specimen, the worse result is obtained with temperature at $15{ }^{\circ} \mathrm{C}$, better performance shows at temperature about $25{ }^{\circ} \mathrm{C}$, and then minor declination in etching values $\left(\Delta R_{a}\right)$ is observed at $35^{\circ} \mathrm{C}$. The results indicate that the best etching performance is achieved with moderate temperature of $25^{\circ} \mathrm{C}$. 


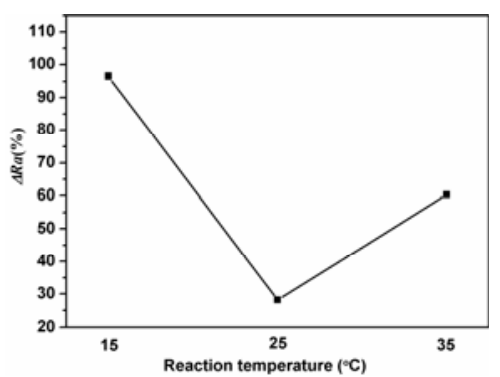

Fig. 1 Surface roughness percentage of DD6 specimens at different etching temperature

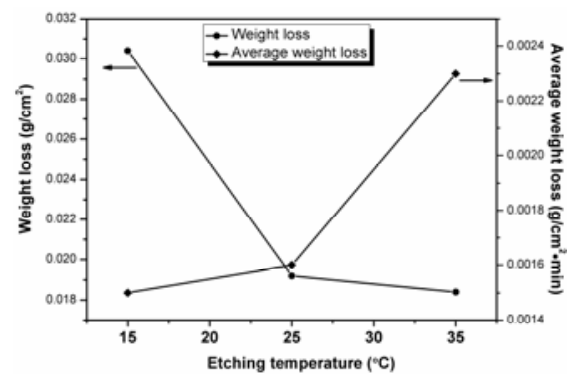

Fig. 2 Weight loss and average etching rate of DD6 specimens at varied etching temperature

To further investigate the dissolution behavior of DD6 single crystal alloy, the weight loss and average etching rate of specimens are calculated. The weight loss caused by the dissolution of metal is shown in Fig. 2. The weight loss first decreases sharply when bath temperature increased from $15{ }^{\circ} \mathrm{C}$ to $25^{\circ} \mathrm{C}$, and finally starts to decline slightly when the bath temperature goes up to $35^{\circ} \mathrm{C}$. In contrast with the weight loss, average etching rate shows the opposite tendency. At first the average etching rate increases slowly, afterwards that increases rapidly.

To observe the changes in the surface morphology of DD6 specimens during the etching process, surface morphologies are investigated. The influence of bath temperature from $15{ }^{\circ} \mathrm{C}$ to $35{ }^{\circ} \mathrm{C}$ on surface morphology of DD6 specimens is shown in Fig. 3, revealing preferential attack of interdendritic region, which is of great concern during acid etching of single crystal superalloy. Specimen has been corroded seriously at cold temperature of $15{ }^{\circ} \mathrm{C}$, leaving an uneven and rough surface. As etching temperature raised, the selective corrosion decreases, performing much smoother surface at moderate temperature. It can be explained that corrosion speed is strongly attached to etching temperature, when the bath is cold, unduly slow action happens, leading to severe interdendritic region attack. However, the corrosion completed faster when the bath temperature increased, preventing specimen from multiple dissolution. This is in accord with the surface roughness and weight loss results.
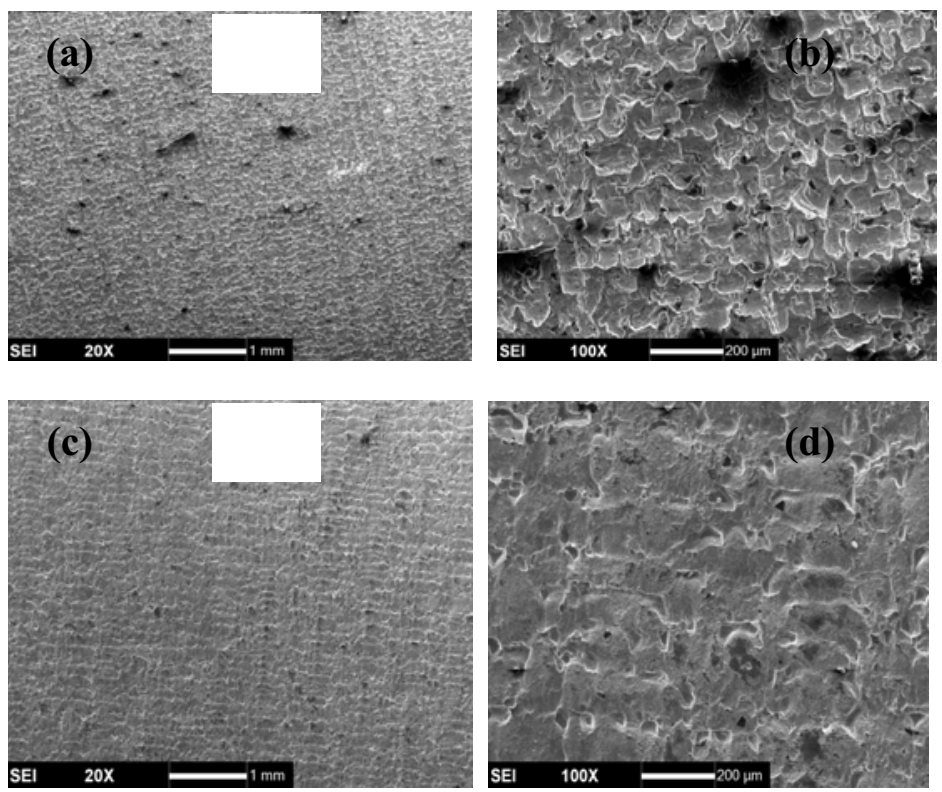


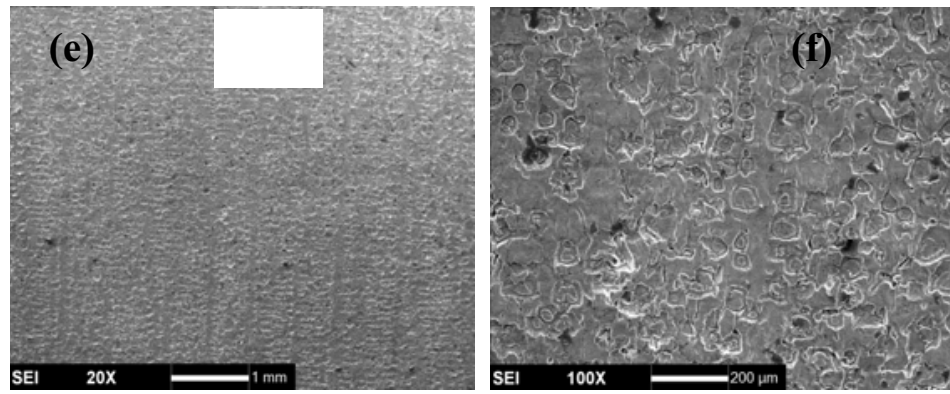

Fig. 3 SEM micrographs of the surface of DD6 specimens after etching at different temperature

(a) (b) $15^{\circ} \mathrm{C}$, (c) (d) $25^{\circ} \mathrm{C}$, (e) (f) $35^{\circ} \mathrm{C}$

The total weight loss may be caused by dissolution of metallic phase, and thin oxide layers or contaminants. The contribution of metal dissolution to the total weight loss is of great concern is this study. It illustrates metal dissolution always begin through the interdendritic region, and chlorine evolution also proceeds in parallel with metal dissolution. Reducing bath temperature prolongs reaction holding time, the selective corrosion increases with time elapsed, and more corroded products can be easily flushed away, leading to a poor surface quality. This may be explained the phenomenon that corrosion at low temperature is even more serious than at high temperature.
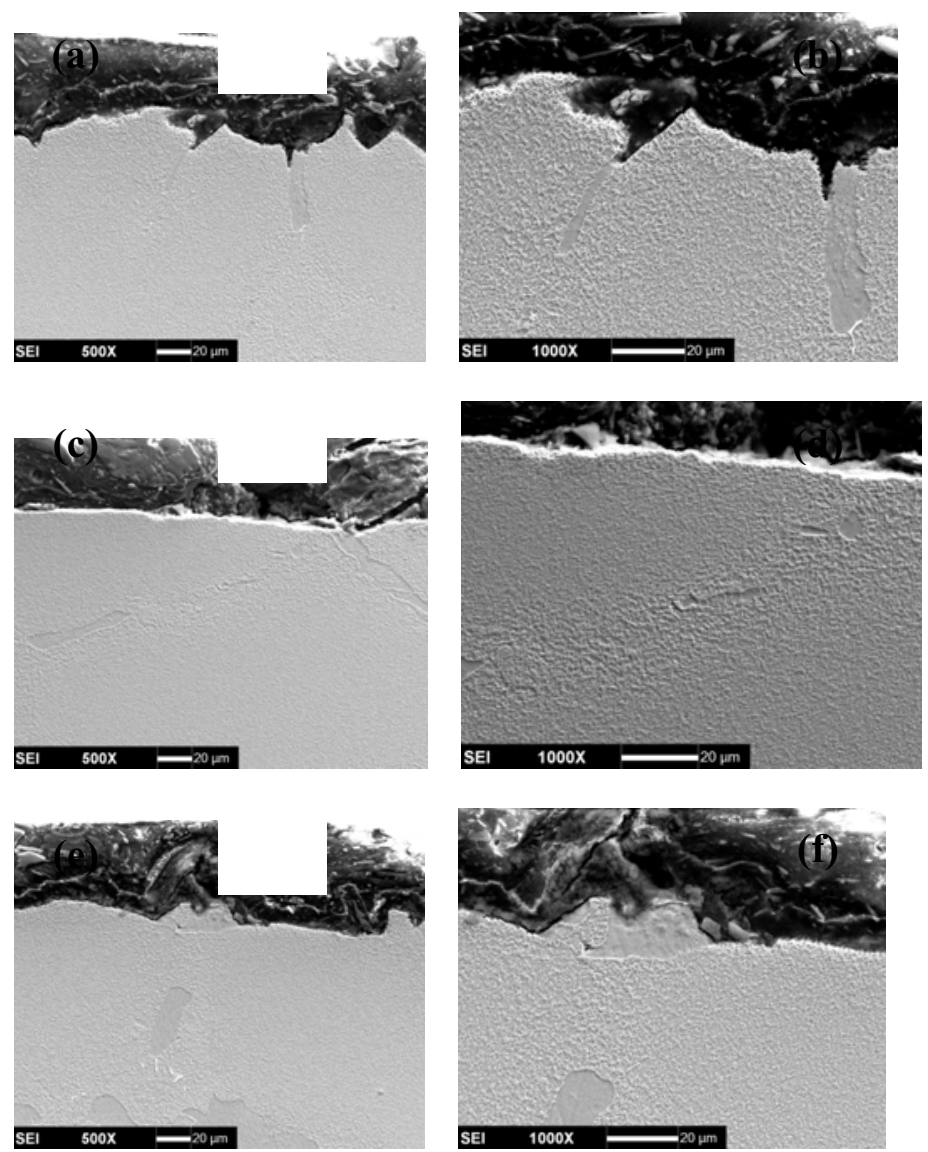

Fig.4 Cross sectional images of DD6 specimens corroded at different temperature (a) (b) $15^{\circ} \mathrm{C}$,

(c) (d) $25^{\circ} \mathrm{C}$, (e) (f) $35^{\circ} \mathrm{C}$ 
The changes in the cross section microstructure of corroded DD6 specimen can be observed from Fig. 4. It can be demonstrated that the most fierce dissolution behavior of metallic phase occurred at $15{ }^{\circ} \mathrm{C}$. Serious selective corrosion can be observed on the specimen surface, forming pits with angles and leading to poor surface. This indicates that preferential attack of $\gamma+\gamma^{\prime}$ eutectic mainly composed of $\gamma^{\prime}$ phase occurred under corrosion, which is explained by that thermodynamic unstable elements that constituted $\gamma^{\prime}$ phase which also distributed in interdendritic region are easily to be corroded.

\section{Conclusions}

(1) Bath temperature has significant impact on surface morphology and surface roughness. The result indicates that cold bath temperature of $15{ }^{\circ} \mathrm{C}$ could cause slow but severe corrosion. Nevertheless, warm bath temperature of $25^{\circ} \mathrm{C}$ lead to a better surface quality.

(2) Bath temperature also has remarkable effect on weight loss and average etching rate. Average etching rate speed up as bath temperature increased, the total weight loss depends on corrosion holding time, which mean that cold bath temperature produce more weight loss.

(3) Selective corrosion preferentially attack interdendritic region and $\gamma^{\prime}$ phase as well, contributed a lot to the decrease of surface quality of DD6 specimens.

\section{References}

1. B. B. Seth, T. M. Pollock, R. D. Kissinger, et al: Superalloys 2000. PA, TMS, 2000, p. 3-16.

2. J. S. Van Sluytman, T. M. Pollock: Acta Materialia Vol. 60(2012), p. 1771-1783.

3. Z. X. Shi, J. R. Li, S. Z. Liu: Trans. Nonferrous Met. Soc. China Vol. 22(2012), p. 534-538.

4. M. Chakravortty, R.K. Paramguru, P. K. Jena: Hydrometallurgy Vol. 59 (2001), p.4554.

5. E. Barmatov, T. Hughes, D. Eskin: Corrosion Science Vol. 103 (2016), p. 196-205.

6. S. M. Lee, W. G. Lee, Y. H. Kim, et al: Corrosion Science Vol. 63 (2012), p. 404-409.

7. J. R. Li, J. Q. Zhao, S. Z. Liu, et al: In Reed R C Superalloys 2008. PA, TMS, 2008, p. 443-451.

8. P.J. Núñeza, E. García-Plazaa, M. Hernandoa, et al: Procedia Engineering Vol. 63 (2013), p. 771-778. 